\section{Ventricular fibrillation in the Antarctic: an unexpected event}

Sir,

Ventricular fibrillation is a common complication of acute myocardial infarction. ${ }^{1}$ This arrhythmia is potentially reversible if direct current cardioversion is promptly administered. ${ }^{2}$ We wish to highlight, with a case report, the benefit of carrying a defibrillator in the medical kit of groups of young, apparently low risk individuals visiting remote parts of the world.

A 42 year old apparently healthy male serving on a British Antarctic Survey ship in the Antarctic, developed severe central chest pain whilst supervising one of the regular life-boat drills. This came on after a brief period of vigorous activity (enthusiastic cranking of a stubborn engine). Half an hour later, on return to the mother ship, the pain worsened and he sought medical attention.

An initial limited electrocardiogram (ECG) demonstrated ST elevation in leads II and III, and ST depression in lead I. A subsequent 12 lead ECG confirmed the diagnosis of an inferior myocardial infarction.

Within the hour he had a cardiac arrest. This was secondary to ventricular tachycardia which degenerated into ventricular fibrillation. This was successfully terminated by a single 200 Joule direct current shock, and a lignocaine infusion was administered. The rest of his management was routine and uncomplicated, except that thrombolysis was not available.

Two months post-infarct he was admitted to the Cardiology Unit at Aberdeen Royal Infirmary where cardiac catheterization demonstrated an irregular right coronary artery with a severe distal stenosis, and inferior left ventricular akinesia. Due to the presence of persistent post-infarction angina he subsequently underwent angioplasty and is now symptom free.

The defibrillator was available during what was the first season of its inclusion in the medical indent. Without it, the sailor would certainly have died.

From the Framingham study, the incidence of acute myocardial infarction in men aged 35-44 years is 21 per $10,000 .{ }^{3}$ The overall mortality of acute myocardial infarction is $50 \%$, and half of these deaths occur in the first 2 hours, mostly from ventricular fibrillation. ${ }^{1}$

In the absence of left ventricular failure or cardiogenic shock, ventricular fibrillation related to acute myocardial infarction is nearly always correctable. ${ }^{1}$ We therefore recommend the routine package of a defibrillator in the medical kit of those serving in remote areas.

Stephen J. Cross, Roy A.A. O'Conor, ${ }^{\prime}$ Alan H. Milne, MRCGP,

Kevin P. Jennings

Department of Cardiology,

Aberdeen Royal Infirmary, Foresterhill, Aberdeen $A B 92 Z D$, and ${ }^{1}$ British Antarctic Survey Medical Unit, Robert Gordon's Institute of Technology, Survival Centre, King Street, Aberdeen $A B 23 B J, U K$.
References

1. Pentecost, B.L. Myocardial infarction. In: Wetherall, D.J., Ledingham, J.G.G. \& Warrel, D.A. (eds). Oxford Textbook of Medicine, 2nd ed. Oxford Medical Press, Oxford, 1987, 13, pp. 167-182.

2. Pasternak, R.C., Braunwald, E. \& Sobel, B.S. Acute myocardial infarction. In: Braunwald, E. (ed.). Heart Disease, $A$ Textbook of Cardiovascular Medicine, 3rd ed. WB Saunders, Philadelphia, 1988, pp. 1222-1313.

3. Kannel, W.B. \& Thom, T.J. Incidence, prevalence, and mortality of cardiovascular diseases. In: Hurst, J.W. (ed.) The Heart, 6th ed. McGraw-Hill Book Company, New York, 1985, pp. $557-565$.

\section{Fluconazole-associated acute adrenal insufficiency}

Sir,

Adrenal insufficiency is a recognized complication of the acquired immunodeficiency syndrome (AIDS). We wish to report a case of acute adrenal insufficiency that occurred in a patient with AIDS due to the oral antifungal agent fluconazole.

A 34 year old Hispanic male was admitted in August 1989 with complaints of progressive weight loss, fevers and odynophagia. He had a prior history of AIDS with Pneumocystis carinii pneumonia and cytomegalovirus (CMV) retinitis. Physical examination revealed generalized wasting, a temperature of $39^{\circ} \mathrm{C}$ and oral candidiasis. His serum electrolytes were entirely normal. He was given zidovudine $100 \mathrm{mg}$ by mouth every $4 \mathrm{~h}$ and was started on oral ketoconazole but did not demonstrate any clinical response. On 1 October 1989 he was started on ampho-흘 tericin B with partial resolution of the oral candida and odynophagia. Fluconazole was approved for the patient on 17 October 1989 and he was started on $200 \mathrm{mg}$ by mouth per day. Three weeks later he developed hyperkalaemia $(6.1 \mathrm{mmol} / \mathrm{l})$, hyponatraemia $(134 \mathrm{mmol} / \mathrm{l})$, and low serum bicarbonate $(17 \mathrm{mmol} / \mathrm{l})$. There was no elevation in creatinine or blood urea nitrogen levels. A synthetic ACTH stimulation test revealed a baseline cortisol level of less than $0.5 \mu \mathrm{g} / \mathrm{dl}$ that failed to rise $30 \mathrm{~min}$ post-stimulation. A diagnosis of acute adrenal insufficiency was made. The fluconazole was stopped and steroid replacement begun. The electrolyte abnormalities resolved. An abdominal computed tomographic scan failed to reveal any demonstrable gross adrenal pathology. The patient died 2 weeks later. Permission for a post-mortem examination was not obtained.

Ketoconazole is known to produce adrenal suppression. ${ }^{1}$ The basis for adrenal suppression by the azole anti-fungal agents is by suppression of the cytochrome P-450 enzyme system in the adrenal cells.' In consequence, ketoconazole has been used to treat Cushing's syndrome utilizing this property. ${ }^{2}$ Adrenal suppression in humans by fluconazole has not been previously reported. ${ }^{3,4}$ Studies in rats have however shown a suppressive effect in vitro of fluconazole on the adrenal P-450 system, ${ }^{5}$ but the concentration of fluconazole required to produce suppression of adrenal steroid production in this model was two orders of magnitude higher than the concentration of ketoconazole required to produce a similar effect.

In light of the clinical presentation in our case, we propose that the patient developed acute fluconazole- 
induced adrenal suppression as part of his terminal illness. He did have a history of disseminated cytomegalovirus infection which can be associated with adrenal failure and acute Addisonian crisis in patients with AIDS. A post-mortem was not obtained to study the adrenal tissue, but the temporal association of the adrenal failure with administration of fluconazole makes us feel that it was the causative factor. The ketoconazole is unlikely to have affected the adrenals as it was discontinued 38 days prior to the development of the adrenal insufficiency.

In light of this case, we feel that it is prudent to recommend that patients being treated with fluconazole should be monitored for the onset of signs and symptoms consistent with adrenal insufficiency.

Jeremy D. Gradon* Douglas V. Sepkowitz Division of Infectious Diseases, Maimonides Medical Center. 4802 Tenth Avenue,

Brooklyn, New York 11219, USA. *Correspondence: 11305 Baroque Road, Silver Springs, Maryland 20901, USA.

\section{References}

1. Sonino, $\mathbf{N}$. The use of ketoconazole as an inhibitor of steroid production. $N$ Engl J Med 1987, 317: 812-818.

2. McCance, D.R., Kennedy, L., Sheridan, B. \& Atkinson, A.B. Ketoconazole as an inhibitor of steroid production. $N$ Engl $J$ Med 1988, 318: 710.

3. Lazar, J.D. \& Wilner, K.D. Drug interactions with fluconazole. Rev Infect Dis 1990, 12 (Suppl): S327-S333.

4. Rieth, H. \& Sauerbrey, N. Interaction studies with fluconazole, a new tri-azole anti-fungal drug. Wien Med Wochenschr 1989, 139: $370-374$.

5. Eckhoff, C., Oelkeb, W. \& Bahr, V. Effects of two antimycotics, ketoconazole and fluconazole upon steroidogenesis in rat adrenal cells in vitro. $J$ Steroid Biochem 1988, 31: 819-823.

\section{Changes in AVP following aggressive diuretic therapy of severe congestive cardiac failure in elderly patients}

Sir,

Congestive cardiac failure (CCF) is a progressive disorder and is associated with a high mortality, particularly in more advanced stages. Clinical, non-invasive and invasive methods used in the assessment of heart failure are unreliable. ${ }^{1}$ Plasma arginine vasopressin (AVP) levels have been shown to rise in CCF and fall towards normal after successful treatment, ${ }^{2,3}$ reflecting part of the neurohormonal response to cardiac failure whose purpose is to restore circulatory homeostasis.

In a prospective study of 13 elderly patients (aged 75-90 years) with New York Heart Association (NYHA) Class 3 and $4 \mathrm{CCF}$, we assessed the changes in plasma AVP levels which occurred during aggressive diuretic therapy over a period of 7 days. Changes in plasma AVP levels in 13 age and sex matched normal subjects were also determined over the same period. Prior to the study, patients were all being treated with frusemide (mean daily dosage $40 \mathrm{mg}$ ), amiloride (mean daily dosage $5 \mathrm{mg}$ ), and 6 patients were on digoxin therapy (mean daily dosage $0.10 \mathrm{mg}$ ). None was being treated with angiotensin converting enzyme inhibitors.

Pretreatment samples for urea, electrolytes, creatine and AVP were taken and the CCF patients were commenced on oral frusemide combined with metolazone (mean daily dosages $70 \mathrm{mg}$ and $6.25 \mathrm{mg}$ respectively). Dosages were adjusted daily according to clinical changes and biochemistry.

At the end of the study period, all patients with CCF had improved clinically and symptomatically with a mean weight loss of $6 \mathrm{~kg}(P=0.0001)$. Mean plasma creatinine increased from 104.9 to $120.8 \mathrm{pmol} / \mathrm{l}$, but there were no other significant biochemical abnormalities. Mean plasma AVP fell from $4.13 \mathrm{pmol} / 1$ to $2.07(P=0.005)$ in the CCF group, but was unchanged (0.83 vs 0.97 ; $P=0.805$ ) in normal subjects over the same period. It is notable that those patients initially classified as NYHA class 4 displayed a very wide range of AVP levels (1.1-12.9 pmol/l), with 4 of these having levels greater than $8 \mathrm{pmol} / \mathrm{l}$.

High plasma AVP levels in CCF are associated with lower cardiac indices, elevated plasma renin, adrenaline and aldosterone levels, all of which may indicate a relatively poor prognosis. ${ }^{4}$ We conclude therefore that within the category of severe heart failure as assessed by the NYHA classification there lies a subgroup of patients with a more unfavourable prognosis who may require prolonged aggressive therapy and more frequent followup. Plasma AVP levels provide a non-invasive means of identifying these patients.

E. Mulkerrin, M.D. Penney, ${ }^{1}$ K. Donovan, D. Hampton, ${ }^{1}$ J. Arnold ${ }^{2}$ D. Sykes Department of Geriatric Medicine, St Woolos Hospital, Newport, Gwent;

${ }^{\prime}$ Department of Chemical Pathology, Royal Gwent Hospital, Newport, Gwent;

${ }^{2}$ Cardiff Royal Infirmary, Newport Road, Cardiff, $U K$.

\section{References}

1. Packer, M. How should we judge the efficacy of drug therapy in patients with chronic congestive heart failure? The insights of six blind men. J Am Coll Cardiol 1987, 9: 433-438.

2. Fyhrquist, F. \& Tikkanen, I. Antidiuretic hormone and atrial natriuretic peptide in congestive heart failure. Acta Med Scand 1986, 707 (Suppl): 55-60.

3. Broqvist, M., Dahlstrom, U.M., Karlberg, B.E. et al. Neuroendocrine response in acute heart failure and the influence of treatment. Eur Heart J 1989, 10: 1075-1083.

4. Bichet, D.G., Kortas, C., Mettauer, B. et al. Modulation of plasma and platelet vasopressin by cardiac function in patients with heart failure. Kidney Int 1986, 29: 1188-1196. 